\title{
Study of straw proportional tubes for a transition radiation detector/tracker at $\mathrm{LHC}$
}

\author{
T. Åkesson ${ }^{1}$, V. Bondarenko ${ }^{2}$, V. Bychkov ${ }^{3}$ E. David ${ }^{4}$, N. D. Dixon ${ }^{4}$, \\ B. Dolgoshein ${ }^{2}$, C. W. Fabjan ${ }^{4}$, Ph. Farthouat ${ }^{4}$, D. Froidevaux ${ }^{4}$, W. Fuchs ${ }^{4}$, \\ S. Furletov ${ }^{2}$, I. Gavrilenko ${ }^{4}$, V. Grigoriev ${ }^{2}$, C. Hauviller ${ }^{4}$, J. W. Hiddleston ${ }^{5}$, \\ M. Holder ${ }^{6}$, V. G. Ivochkin ${ }^{7}$ O. Kondratiev ${ }^{2}$, S. Konovalov ${ }^{8}$, P. Lichard ${ }^{4}$, \\ S. Muraviev ${ }^{8}$, P. Malecki ${ }^{9}$, N. McCubbin ${ }^{5}$, A. V. Nadtochi ${ }^{7}$, P. Nevski ${ }^{4}$, \\ P. R. Norton ${ }^{5}$, S. Pavlenko ${ }^{2}$, V. Peshekhonov ${ }^{3}$, C. Raine ${ }^{10}$, R. Richter ${ }^{11}$, \\ A. Romaniouk ${ }^{2}$, D. H. Saxon ${ }^{10}$, V. A. Schegelsky ${ }^{7}$, S. Semenov ${ }^{2}$, A. Shmeleva ${ }^{8}$, \\ S. Smirnov ${ }^{2}$, V. Sosnovtsev ${ }^{2}$, E. M. Spiridenkov ${ }^{7}$, M. Stavrianakou ${ }^{10}$, D. J. White ${ }^{5}$, \\ A. Wilson ${ }^{10}$, N. Zaganidis ${ }^{4}$

\begin{abstract}
The most relevant properties for operation of straw proportional tubes at LHC are described. Particular attention is paid to the possibility of straw operation in a strong magnetic field and a high radiation environment.
\end{abstract}

\footnotetext{
${ }^{1}$ University of Lund, Sweden

${ }^{2}$ Moscow Engineering and Physics Institute, Moscow, Russia

${ }^{3}$ JINR(Dubna), Russia

${ }^{4}$ CERN, Geneva, Switzerland

${ }^{5}$ Rutherford Appleton Laboratory, Didcot, UK

${ }^{6}$ Siegen University, Germany

${ }^{7}$ Nuclear Physics Institute, St. Petersbourg, Russia

${ }^{8}$ P. N. Lebedev Institute of Physics, Moscow, Russia

${ }^{9}$ Institute of Nuclear Physics, and Academy of Mining and Metallurgy, Krakow, Poland

${ }^{10}$ Glasgow University, UK

${ }^{11}$ MPI, Munich, Germany
} 


\section{Contents}

1 Introduction 3

2 Mechanical properties of the straw tubes 3

3 Electrical properties of the straw tubes 5

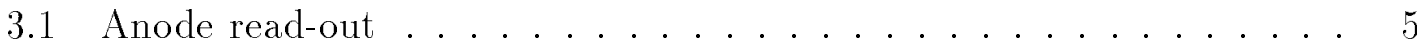

3.2 Cathode read-out . . . . . . . . . . . . . 7

4 Operating properties at LHC 9

4.1 Straw operation in a 2 Tesla magnetic field . . . . . . . . . . . 9

4.2 Straw counting rate due to charged particles and neutrons . . . . . 11

4.3 Ageing properties of the straw tubes . . . . . . . . . . . 14

4.4 Space charge effects and straw performance at high fluxes of ionizing particles .......................... 15

4.5 Ion tail measurements in the straw tubes . . . . . . . . . 16

4.6 Straw tube performance at high counting rate .......... 17

5 Monte-Carlo (MC) simulation of the straw response 21

6 Conclusions $\quad 22$

$\begin{array}{lll}7 & \text { Acknowledgements } & 23\end{array}$ 


\section{Introduction}

This paper reports on detailed studies performed in the context of RD6 [1, 2, 3, 4], with the goal of developing a transition radiation straw tracker (TRT) for the ATLAS experiment [5] at LHC. Systematic measurements of the mechanical (Section 2) and electrical (Section 3) properties of proportional Kapton straw tubes are described, and followed in Section 4 by a detailed discussion of the operation of such straw tubes in a magnetic field, and in the high-radiation and high-rate environment of LHC. Finally, Section 5 compares the measured performances to those expected from a detailed model of the straw response.

\section{Mechanical properties of the straw tubes}

The straw proportional tubes for the TRT detector in ATLAS are prepared from a Kapton film, which contains on one side a conductive layer of 1000 to $3000 \AA \mathrm{Al}+$ $4 \mu \mathrm{m}$ Carbon-loaded Kapton, and on the other a thermoplastic polyurethane layer of $\sim 3 \mu \mathrm{m}$. The manufacturing process is performed on a precisely tooled mandrel, on which two Kapton-film tapes (4-8 $\mathrm{mm}$ wide) are wound in spirals at a temperature of $\sim 200{ }^{\circ} \mathrm{C}$, as shown in Fig. 1 . This process may provide straws of up to $5 \mathrm{~m}$ length. A cut through the straw wall is shown in Fig. 2. The total resulting straw wall thickness is about $60 \mu \mathrm{m}$. The straw wall thus has conductive layers on both sides. The properties of such straws have been investigated and some basic characteristics are given in Table 1 .

Studies have shown that to keep the straw straight, it has to be stretched by a force not less than $200 \mathrm{~g}$ [5]. The problem which may then arise is that the straw material may flow with time; this would reduce the original straw tension and could be a major source of concern for the long term stability of a large system.

Figure 3 shows the elongation of straws of $50 \mathrm{~cm}$ length versus time under a load of $200 \mathrm{~g}$. A continuous but erratic elongation of the straws is observed versus time, but the comparison of these data with the measurements of humidity during the same period (Fig. 4) shows a strong correlation between elongation and humidity. This measurement shows strikingly the sensitivity of the straw mechanical properties to humidity.

At constant humidity no changes in the straw length within an accuracy of $10 \mu \mathrm{m}$ have been found, over a period of more than three months [4]. In Fig. 5 is shown the uniformity of the gas gain along the straw, which contains information about the straw straightness, for two different straws versus humidity. The straws had been pre-stretched by a $200 \mathrm{~g}$ load and their ends had then been fixed. It follows from these measurements that a humidity of more than $70 \%$ is damaging for the mechanical stability of Kapton straws. 
Table 1: Mechanical properties of Kapton straw tubes

\begin{tabular}{|c|c|}
\hline Diameter & $4 \mathrm{~mm}$ \\
\hline Wall thickness & $60 \mu \mathrm{m}$ \\
\hline Young's modulus of straw material & $300 \mathrm{~kg} / \mathrm{mm}^{2}$ \\
\hline Relative elongation at $200 \mathrm{~g}$ load & $10^{-3}$ \\
\hline Temperature coefficient of elongation & $3 \cdot 10^{-5}{ }^{\circ} \mathrm{K}^{-1}$ \\
\hline Anode wire diameter (gold-plated Cu-Be) & $50 \mu \mathrm{m}$ \\
\hline Anode wire tension & $50 \mathrm{~g}$ \\
\hline
\end{tabular}

Table 2: Mechanical properties of reinforced straw tubes

\begin{tabular}{|c|c|}
\hline Number of carbon fibres & 3 \\
\hline Relative elongation at $200 \mathrm{~g}$ & $6 \cdot 10^{-5}$ \\
load & \\
\hline Temperature coefficient of elongation & $3 \cdot 10^{-6}{ }^{\circ} \mathrm{K}^{-1}$ \\
\hline
\end{tabular}

The gas gain uniformity along the straw as a function of temperature is shown in Fig. 6 for three different straws. There is no essential deterioration of the uniformity up to $65{ }^{\circ} \mathrm{C}$. To check the operational stability of straws with fixed ends, a special prototype was made, containing 30 straws of $33 \mathrm{~cm}$ length. No changes in the gas gain uniformity of any of the straws were observed over more than one year under stable conditions.

To solve the problems of straw instability due to various factors (humidity, temperature, load), a solution has been developed for the full-scale TRT wheel engineering prototype. It consists in reinforcing the straw walls with carbon fibres, which are glued along the straw. Each fibre contains about 500 to 1000 filaments of $7 \mu \mathrm{m}$ diameter, which does not result in a too large increase of the straw wall mass, 20 to $40 \%$ depending on the number of filaments per fibre and on the number of fibres $(3$ or 4$)$ glued to the straw. Such reinforced straws were tested for sensitivity 
to humidity. It was found that there is no significant change of the straw properties even for a humidity of $100 \%$ (at least for 24 hours), as shown in Fig. 5.

Some of the mechanical properties of such reinforced straws are given in Table 2. At the cost of a modest increase of the straw weight (and therefore radiation length), their mechanical rigidity and stability can be improved at least by one order of magnitude. An automatic machine for mass production of reinforced straws is under operation now at CERN.

The gas gain uniformity along the straw which is desired by construction is not more than $5 \%$. Figure 7 shows what this means from the point of view of straw straightness or wire eccentricity (the data are shown for a gas mixture of $70 \% \mathrm{Xe}+20 \% \mathrm{CF}_{4}+10 \% \mathrm{CO}_{2}$ ). The gas gain (or signal amplitude) was measured as the peak position in amplitude distribution (even for asymmetrical distribution). A $250 \mu \mathrm{m}$ offset of the wire inside the straw results in a gas gain change of $4 \%$. In practice the wire inside the straw is quite straight and the observed gas gain non-uniformities usually correspond to some curvature of the straw.

Possible deflections of the wire due to electrostatic forces $(\mathrm{F})$ can be estimated from the following equation [6]:

$$
F=\frac{2 \pi \varepsilon_{0} V^{2} \delta}{b^{2}\left(\ln \left(\frac{b}{a}\right)\right)^{2}},
$$

where $\mathrm{V}$ is the anode wire potential, a is the anode wire radius, $\mathrm{b}$ is the cathode radius, and $\delta$ is the wire offset.

The deflection d due to electrostatic forces is:

$$
d=\frac{L^{2} F}{8 T},
$$

where $\mathrm{L}$ is the straw length and $\mathrm{T}$ is the tension of the wire.

$$
d=\frac{2 \pi \varepsilon_{0} V^{2} L^{2}\left(\frac{\delta+d}{2}\right)}{8 T b^{2}\left(\ln \frac{b}{a}\right)^{2}} .
$$

For $\mathrm{L}=1 \mathrm{~m}, \mathrm{~T}=50 \mathrm{~g}$ and $\mathrm{V}=1800 \mathrm{~V}$ we obtain $\mathrm{d}=0.4 \delta$. Such a deflection could be large for $1 \mathrm{~m}$ long wires with large offsets, typically $100 \mu \mathrm{m}$ for an offset of $250 \mu \mathrm{m}$. The maximum deflection of the wire due to gravitation is about $45 \mu \mathrm{m}$ for a $50 \mu \mathrm{m}$ diameter and $1 \mathrm{~m}$ long $\mathrm{Cu}$-Be wire.

\section{Electrical properties of the straw tubes}

\subsection{Anode read-out}

In the case of anode read-out, the cathode resistance has to be as low as possible. As already mentioned in Section 2, a thin Al layer was introduced between Kapton 
film and Carbon-loaded Kapton layer for this purpose. Two such conductive layers, placed on the inside and outside surface of the straw wall do not result in any significant increase of the straw material thickness, but give additional robustness in case of cathode conductive layer damage (for example due to accidental breakdowns). It has been shown experimentally that after several breakdowns at one point in the straw, the resistance of the inner cathode layer sharply increases (up to $30 \mathrm{k} \Omega$ ), which is fatal for a straw with one single conductive layer. On the other hand, the fast signal propagation characteristics of a straw with a double conductive layer remain unchanged in the same situation.

The fast signal propagation properties depend on the cathode and anode resistance. The anode wire resistance is about $60 \Omega$ per meter for a DC current. For a real signal with a rise time of $10 \mathrm{~ns}(25 \mathrm{~ns}$ at the base for a central frequency of about $20 \mathrm{MHz}$ ), the anode resistance remains the same due to the quite large skin depth of the $\mathrm{Cu}-\mathrm{Be}$ wire (about $25 \mu \mathrm{m}$ at $20 \mathrm{MHz}$ ).

The cathode resistance of the Kapton straw is about $400-800 \Omega$ per meter long straw, and depends on the width of the tape from which the straws are produced. In the case of straws reinforced by carbon fibres, the propagation properties are improved due to the low resistance of the carbon fibres. The attenuation properties of these different types of straws were measured directly. It was found that, for a signal with a rise time of $10 \mathrm{~ns}$, the attenuation length is $2-3 \mathrm{~m}$ (depending on the width of the tape) for straws without $\mathrm{C}$-fibres, and $4 \mathrm{~m}$ for straws with $\mathrm{C}$-fibres.

For coaxial structures such as these straw tubes, the characteristic impedance may be calculated using:

$$
Z_{0}=60 \ln (b / a)
$$

for an ideal loss-free line. If the anode and cathode have significant series resistance, the characteristic impedance will be frequency dependent:

$$
Z_{0}=\sqrt{(R+j \omega L) /(G+j \omega C)}
$$

where $\mathrm{R}$ is the resistance, $\mathrm{L}$ the inductance, $\mathrm{G}$ the conductance and $\mathrm{C}$ the capacitance, all per unit length. $G$ is usually negligible and therefore:

$$
Z_{0}=\sqrt{(R+j \omega L) / j \omega C)}
$$

If $\mathrm{R}$ is small, the impedance will be $260 \Omega$. It was shown experimentally, that for the straw tube parameters given in Table 3 , the optimal termination resistance is about $300 \Omega$.

In the following, only unterminated straw tubes are discussed, since the studies done in RD6 performed only for straws of less than $1 \mathrm{~m}$ length. Connection to the front-end electronics is shown schematically in Fig. 8. The coupling capacitor $\left(\mathrm{C}_{c}\right)$ 
is shared between several (typically 4 to 16 ) straws, which are connected to the HV through a $H V$ resistor-fuse $\left(\mathrm{R}_{H V}\right)$, with a nominal value of $100 \mathrm{k} \Omega$. This electrical chain is characterized by only one time constant, $\tau=\mathrm{R}_{H V} \cdot \mathrm{C}_{c}=200 \mu \mathrm{s}$. The discharge current of this chain goes through the input of the preamplifier and has the same polarity as the fast signal from the straw. The most important electrical characteristics of the straws are given in Table 3 .

In large systems containing thousands of elements, some protection against catastrophic breakdowns (for example in case of broken wires) has to be foreseen. On the other hand, it should preserve the electrical contact through the high-voltage chain in case of accidental breakdowns, which means that disconnection should occur only in case of a large continuous current through the straw. We have therefore designed special fuses, switched on as shown in Fig. 8. The basic idea is to use the heating-up of a resistor (for example of $100 \mathrm{k} \Omega$ ) in case of a short-circuit inside a straw. A special spring was connected to the resistor by a solder with a well-defined melting point $\left(190^{\circ} \mathrm{C}\right.$ for the prototypes which were tested).

The time needed to disconnect the HV chain for different currents is shown in Fig. 9 (for resistor values of 0.9 to $2.9 \mathrm{M} \Omega$ ). As can be seen, for $\mathrm{R}=940 \mathrm{k} \Omega$, the faulty channel may be disconnected in one minute for a current of $1 \mathrm{~mA}$. Of course this is just an example of the principle of operation of the fuse. It is clear that its final parameters (size, current, solder melting point) have to be optimized further for operation at LHC. We also note that, in case of disconnection of a faulty channel, all straws connected to the same coupling capacitor will also be disconnected.

\subsection{Cathode read-out}

Some possibilities of cathode read-out for the straw tubes have been described in $[7,8]$. In these publications two approaches were used. The first one is readout through a very highly resistive cathode $\left(10^{5} \Omega / \mathrm{cm}^{2}\right)$ [7]. In this case the straw wall becomes transparent to electrical signals, which can be read out by strips placed outside the straw. The disadvantage of this approach is the limitation of rate capability because of the high cathode resistance (high voltage drop along the straw). The second approach is read-out through a window in a highly conductive cathode [8]. In that case the amplitude of the signal on the strips is limited by the width of the window.

The possibility of cathode read-out with an intermediate cathode resistance (about $1000 \Omega / \mathrm{cm}^{2}$ ) has been studied. As already mentioned, the Kapton straw contains two conductive layers, one inner and one outer. The capacitance between these layers is about $100 \mathrm{pF} / \mathrm{cm}$. This provides the possibility of reading out the fast signal from the inner conductive layer. For these studies two types of straws were produced. In both cases a resistance of the inner layer of $1000 \Omega / \mathrm{cm}^{2}$ was chosen. The outer layer resistance was $5 \Omega / \mathrm{cm}^{2}$ for the first straw and $1000 \Omega / \mathrm{cm}^{2}$ for the 
Table 3: Electrical properties of the straw tubes

\begin{tabular}{|c|c|}
\hline Cathode conductive layer & $2000^{\circ} \mathrm{A} 1+4 \mu \mathrm{m}$ C-loaded Kapton \\
\hline Resistance of the conductive layer & $3-5 \Omega$ per square \\
\hline Resistance of the conductive layer & \\
\hline without Al layer & more than $1000 \Omega$ per square \\
\hline $\begin{array}{l}\text { Cathode resistance (with } \mathrm{Al} \text { ) } \\
\text { for a one meter long straw }\end{array}$ & $400-800 \Omega$ \\
\hline $\begin{array}{l}\text { Anode wire resistance } \\
\text { (for one meter of } 50 \mu \mathrm{m} \mathrm{Cu-Be} \mathrm{wire)}\end{array}$ & $60 \Omega$ \\
\hline Skin depth for $\mathrm{Cu}-\mathrm{Be}$ alloy at $25 \mathrm{MHz}$ & $25 \mu \mathrm{m}$ \\
\hline $\begin{array}{l}\text { Capacitance of assembled } \\
\text { straw for one meter length }\end{array}$ & $20 \mathrm{pF}$ \\
\hline Anode wire inductance & $1600 \mathrm{nH}$ \\
\hline $\begin{array}{l}\text { Straw impedance }\left|Z_{0}\right| \\
\text { (measured at } 30 \mathrm{MHz} \text { ) }\end{array}$ & $300 \Omega$ \\
\hline The best passive termination & $300-330 \Omega$ \\
\hline Signal attenuation length: & \\
\hline without carbon fibres & $2-3 \mathrm{~m}$ \\
\hline with carbon fibres & $4 \mathrm{~m}$ \\
\hline Signal propagation time & $4 \mathrm{~ns} / \mathrm{m}$ \\
\hline $\begin{array}{c}\text { Capacitance between two cathode } \\
\text { layers }\end{array}$ & $100 \mathrm{pF} / \mathrm{cm}$ \\
\hline
\end{tabular}


second one. To read out the cathode signal in the first straw the outer layer had to be divided into some number of isolated rings (or pads) as shown in Fig.10. In our tests a width of $15 \mathrm{~mm}$ was chosen for the rings. Amplifiers with input resistors of $50 \Omega$ were then directly connected to these rings. High voltage was applied to the anode. The signals obtained from a collimated $6 \mathrm{keV} \mathrm{X}$-ray source on anode and cathode are shown in Fig.11. The source was positioned at the middle of the ring, and the observed cathode pulse shape was compatible to the anode one. Fig.12 shows the average charge sharing observed between cathode rings for different positions of the source (step of $2 \mathrm{~mm}$ ). This sharing is not sensitive to the exact source position over at least $\pm 6 \mathrm{~mm}$ from the ring center.

To improve the position accuracy the length of the ring would have to be reduced to around $4 \mathrm{~mm}$, at the price of much lager channel count. The last possibility to achieve a reasonably accurate cathode measurement, was to use an outer layer with a resistance of $1000 \Omega / \mathrm{cm}^{2}$. Current amplifiers were connected in the same way as above but the outer conductive layer was not divided into rings. The cathode resistance between two neighbor contacts was about $1500 \Omega / \mathrm{cm}$. The average charge sharing between cathodes is shown in Fig.13 for different source positions. One can see the sensitivity is much better than in the first case.

\section{Operating properties at LHC}

\subsection{Straw operation in a 2 Tesla magnetic field}

At the LHC the ATLAS TRT will be placed in a magnetic field. It is well known that the electron drift velocity in gases depends on the value of the magnetic field, which generally leads to an increase in the total signal collection time.

Dedicated measurements of the drift velocity and Lorentz angles in a magnetic field of 2 Tesla were performed for the reference gas mixture of $70 \% \mathrm{Xe}+20 \% \mathrm{CF}_{4}+$ $10 \% \mathrm{CO}_{2}$. The main measurements have been done on the experimental setup of Rutherford Appleton Laboratory [9]. Experimental results are shown in Figs. 14, 15 and 16. The experimental data are compared with the results of simulations using the MAGBOLTZ program $[10]$ for $\mathrm{H}=0$ and $\mathrm{H}=2 \mathrm{~T}$.

The comparison of Fig. $14(\mathrm{H}=2 \mathrm{~T})$ and Fig. $16(\mathrm{H}=0)$ shows that the peak drift velocity is slightly higher in the magnetic field. There is only a $7 \%$ difference between the calculations and the experimental results at this peak value for $\mathrm{H}=2 \mathrm{~T}$. Figure 15 good agreement between measurements and calculations for of the Lorentz angle for electrons as a function of the electric field. Finally the predicted drift velocity component, parallel to the electric field, which defines the total signal collection time, is shown in Fig. 17 for $H=0$ and 2 T. This parallel component of the drift velocity is smaller in the magnetic field than that without magnetic field in the $1 \mathrm{~mm}$ region near the cathode (electric field less than $4 \mathrm{kV} / \mathrm{cm}$ ). 
Table 4: Total electron collection time for straw tubes in a $2 \mathrm{~T}$ field

\begin{tabular}{|c|c|c|c|c|}
\hline Gas mixture & $\begin{array}{c}\text { Straw } \\
\text { diameter } \\
(\mathrm{mm})\end{array}$ & $\begin{array}{c}\text { Gas } \\
\text { pressure } \\
\text { (atm.) }\end{array}$ & $\begin{array}{c}\text { Xe content } \\
\text { norm. in mass } \\
\text { to ref. gas }\end{array}$ & $\begin{array}{c}\text { Total } \\
\text { collection } \\
\text { time (ns) }\end{array}$ \\
\hline $70 \% \mathrm{Xe}+20 \% \mathrm{CF}_{4}+10 \% \mathrm{CO}_{2}$ & 4.0 & 1.0 & 1.0 & 38 \\
& 3.5 & 1.0 & 0.85 & 32 \\
\hline $60 \% \mathrm{Xe}+34 \% \mathrm{CF}_{4}+6 \% \mathrm{CO}_{2}$ & 4.0 & 1.1 & 0.93 & 33 \\
& 3.5 & 1.1 & 0.825 & 27.3 \\
& 3.5 & 1.2 & 0.9 & 27.2 \\
\hline $55 \% \mathrm{Xe}+39 \% \mathrm{CF}_{4}+6 \% \mathrm{CO}_{2}$ & 4.0 & 1.0 & 0.78 & 32 \\
& 3.5 & 1.2 & 0.81 & 26 \\
& 3.5 & 1.4 & 0.95 & 26 \\
\hline $50 \% \mathrm{Xe}+44 \% \mathrm{CF}_{4}+6 \% \mathrm{CO}_{2}$ & 4.0 & 1.2 & 0.84 & 30 \\
& 3.5 & 1.4 & 0.88 & 25 \\
\hline
\end{tabular}


On the other hand, this component does not depend on the value of the magnetic field over the $1 \mathrm{~mm}$ region near the anode wire.

The MAGBOLTZ program has been checked experimentally through these measurements and thus gives us a flexible tool for optimization of the straw parameters in terms of the total signal collection time. In particular, to make the gas mixture faster, the $\mathrm{CF}_{4}$ content should be increased as much as possible. However, for gas gain stabilization the $\mathrm{CO}_{2}$ content should be at least $6 \%$. A decrease in the Xe concentration leads to a deterioration of the electron-pion separation abilities of the TRT.

Several calculations of the total signal collection time are shown in Table 4. For the reference gas mixture mentioned above and a cathode diameter of $4 \mathrm{~mm}$, the total signal collection time is $38 \mathrm{~ns}$, which can be reduced to less than $30 \mathrm{~ns}$ for a Xe concentration as low as $50 \%$. For a smaller cathode diameter of $3.5 \mathrm{~mm}$, a total signal collection time of $25 \mathrm{~ns}$ (one LHC bunch crossing) can be achieved. In this case, the gas pressure may be increased up to 1.4 atm., in order to preserve the amount of Xe in the straws.

In some mixtures such as $40 \% \mathrm{Ar}+40 \% \mathrm{CF}_{4}+20 \% \mathrm{C}_{4} \mathrm{H}_{10}$ [11], it has been found that the gas gain drops by a factor of 2 in a magnetic field of $2 \mathrm{~T}$. We have therefore checked the gas gain dependence on the value of the magnetic field for our chosen gas mixture $\left(70 \% \mathrm{Xe}+20 \% \mathrm{CF}_{4}+10 \% \mathrm{CO}_{2}\right)$ and found that it does not change from 0 to $2 \mathrm{~T}$ within the $3 \%$ accuracy of the measurement.

\subsection{Straw counting rate due to charged particles and neu- trons}

Under LHC operating conditions, i.e. at the revised nominal design luminosity of $10^{34} \mathrm{~cm}^{-2} \mathrm{~s}^{-1}$, the ATLAS straw tubes will be continuously irradiated by charged particles and neutrons. The charged particles are mostly minimum ionising particles. The straw occupancy, defined as the probability that the straw is hit at a given bunch crossing time, depends on the radial position and length of the straw. For axial straws at small rapidity(barrel), the occupancy of $1 \mathrm{~m}$ long straws is maximal for the innermost layer and has been estimated to be $28 \%$ from a single bunch crossing at a radios of $56 \mathrm{~cm}$, assuming that one bunch crossing corresponds to an average of 18 minimum bias events. For radial straws at larger rapidity and for $50 \mathrm{~cm}<R<100 \mathrm{~cm}$ (endcap) the occupancy is essentially independent of the straw position along the beam and is about $15 \%$. But in this case the density of the charged particles per unit straw length depends on the position along the straw. These occupancies correspond to the maximum rates of particles crossing the straws of $13 \mathrm{MHz}$ in the barrel part and $6 \mathrm{MHz}$ in the endcap part.

The distribution of the neutron flux is quite uniform in the inner tracking volume, as described in [5]. The total fluence of neutrons of all energies (including the 
thermal region) is around $10^{14} \mathrm{~cm}^{-2}$ per year. This gives a flux through the straw surface $\left(50 \cdot 0.4 \mathrm{~cm}^{2}\right)$ of $2 \cdot 10^{8}$ neutrons per second. Obviously this flux will produce a certain rate of background signals in the straw tubes. The energy spectrum of the neutrons depends upon the detailed configuration of the detector system, in particular on the presence or absence of a moderator. The primary flux consists of fast neutrons produced in the calorimeter, however the presence of the moderator shifts this neutron energy spectrum towards the thermal region. To evaluate the neutron induced contribution to the straw counting rate, a dedicated measurement was performed, in operating conditions as close as possible to those expected in ATLAS.

Schematically the experimental setup is shown in Fig. 18. The neutron source used was a ${ }^{239} \mathrm{Pu}$-Be source of fast neutrons but also of gamma radiation. The activity of the source was about $1.6 \cdot 10^{5} \mathrm{~s}^{-1}$ for neutrons and about $6 \cdot 10^{5} \mathrm{~s}^{-1}$ for gammas. The source emits approximately 3.5 photons of $\mathrm{MeV}$ energy per neutron. Several straw tubes of $4 \mathrm{~mm}$ diameter and $12 \mathrm{~cm}$ length were inserted into a polyethylene foam radiator of $16 \mathrm{~cm}$ thickness. A lead shielding was inserted between the straws and the source to suppress the direct gamma radiation. In Fig. 19 the straw spectra for different thicknesses of the lead shield are shown ( 100,150 and $200 \mathrm{~mm}$ ). One finds that a thickness of $200 \mathrm{~mm}$ of lead is enough to absorb more than $95 \%$ of the direct gammas from the $\mathrm{Pu}$-Be source, so we conclude that the measured straw counting rates for such a thickness of lead shielding lead to an upper limit on the background rate induced by neutrons. When a $70 \mathrm{~mm}$ thick polystyrene moderator was inserted between the lead shielding and the straws, the straw counting rate increased significantly (curve 5 in fig. 19). This is due to the fact that the straws and the radiator are then irradiated by slow neutrons and the various $(n, \gamma)$ reactions in the materials of the experimental set-up increase the straw counting rate. The influence of the surrounding material on the straw counting rate in such a geometry has been checked by positioning moderator and lead just behind of the straw-radiator set-up. No changes in counting rate have been found. After a careful evaluation of the neutron flux, the probability for a neutron to induce a hit in a straw was estimated for two ranges of energy depositions in the straw: less than $5 \mathrm{keV}$ (corresponding to the expected energy loss of relativistic particles in the straws) and more than $5 \mathrm{keV}$ (corresponding to the signals expected from transition radiation). The results are shown in Table 5 (a rough estimate of the contributions from slow and fast neutrons to the total neutron flux after the $200 \mathrm{~mm}$ lead shield are also indicated). These data are in a good agreement with the data from [12].

The spectrum of neutrons produced by the source is quite similar to that expected at LHC. A moderator of about $50 \mathrm{~mm}$ thickness is foreseen to be used just in front of the calorimeter. This means that outgoing neutrons from moderator in our experiment can be used to estimate an upper limit on the neutron induced counting rate at LHC. For a normalized neutron fluence of $10^{14} \mathrm{~cm}^{-2}$ per year of operation 
Table 5: Neutron counting rate per $50 \mathrm{~cm}$ long straw at LHC conditions

\begin{tabular}{|c|c|c|c|c|}
\hline & $\begin{array}{c}\text { Shield, } \\
\text { moderator }\end{array}$ & $\begin{array}{c}\text { Neutrons } \\
\text { per straw } \\
\text { at LHC } \\
\left(s^{-1}\right)\end{array}$ & $\begin{array}{c}\text { Straw hit } \\
\text { probability } \\
\text { per neutron }\end{array}$ & $\begin{array}{c}\text { Straw } \\
\text { counting } \\
\text { rate at LHC } \\
\left(s^{-1}\right)\end{array}$ \\
\hline Slow neutrons & $\begin{array}{c}\mathrm{Pb}-200 \\
\text { Polyst.-70 }\end{array}$ & $2 \cdot 10^{8}$ & $(1.3 \pm 0.3) 10^{-3}$ & $2.6 \cdot 10^{5}$ \\
\hline Fast $(84 \%)$ and & Pb-200 & $2 \cdot 10^{8}$ & $(5 \pm 1) \cdot 10^{-4}$ & $1.0 \cdot 10^{5}$ \\
slow $(16 \%)$ neutrons & & & & \\
\hline
\end{tabular}

\begin{tabular}{|c|c|c|c|c|}
\hline $\begin{array}{l}\text { Straw response } \\
\text { for min.ion. } \\
\text { particles and } \\
\text { TR ranges }\end{array}$ & $\begin{array}{l}\mathrm{E} \leq 5 \mathrm{keV} \\
\text { Straw hit } \\
\text { probability } \\
\text { per neutron }\end{array}$ & $\begin{array}{c}\mathrm{E} \leq 5 \mathrm{keV} \\
\text { Straw counting } \\
\text { rate at LHC } \\
\left(s^{-1}\right)\end{array}$ & $\begin{array}{l}\mathrm{E} \geq 5 \mathrm{keV} \\
\text { Straw hit } \\
\text { probability } \\
\text { per neutron }\end{array}$ & $\begin{array}{c}\mathrm{E} \geq 5 \mathrm{keV} \\
\text { Straw counting } \\
\text { rate at LHC } \\
\left(s^{-1}\right)\end{array}$ \\
\hline Slow & $(0.9 \pm 0.2) \cdot 10^{-3}$ & $1.8 \cdot 10^{5}$ & $(0.4 \pm 0.1) \cdot 10^{-3}$ & $0.8 \cdot 10^{5}$ \\
\hline $\begin{array}{l}\text { Fast }(84 \%) \text { and } \\
\text { slow }(16 \%) \text { neutrons }\end{array}$ & $(2.0 \pm 0.4) \cdot 10^{-4}$ & $4.4 \cdot 10^{4}$ & $(3.0 \pm 0.6) \cdot 10^{-4}$ & $6.4 \cdot 10^{4}$ \\
\hline
\end{tabular}


at LHC (pessimistic case), and a $50 \mathrm{~cm}$ straw length, Fig. 20 shows the estimated hit rates and occupancies from charged particles (a) and neutrons (b), for both of the above-mentioned energy deposition ranges. We conclude that the occupancy induced by the neutron background is an order of magnitude less than that due to charged particles.

\subsection{Ageing properties of the straw tubes}

The radiation hardness of the Kapton straw tubes and possible ageing effects have been widely investigated over the past few years $[5,13,14]$. We first briefly summarise the results described in those publications:

1.) The radiation resistance of the Kapton straws is very high. No changes in the straws (gas gain, mechanical properties etc.) were observed for fluences of $4 \cdot 10^{14} \mathrm{~cm}^{-2}$ from fast neutrons and of $1.7 \cdot 10^{15} \mathrm{~cm}^{-2}$ from slow neutrons, and also for ionizing particle doses of $80 \mathrm{Mrad}$. This is equivalent to more than 20 years of operation at the highest LHC luminosities.

2.) No ageing in the straw tubes for a total integrated charge of up to $5 \mathrm{C} / \mathrm{cm}$ was observed, which corresponds to over 8 years of operation at design luminosity.

3.) No etching effects on the straw cathode were observed for a similar integrated charge. This was not the case for a thin unprotected Al-layer.

More recent investigations have shown the appearance under certain conditions of a new phenomenon in straw tubes, which we call transient ageing. It happens only for very high particle rates and low gas flow rates.

The experimental set-up was exactly the same as in [13]. A straw tube of $16 \mathrm{~cm}$ long was irradiated by a broad $(8 \mathrm{~cm})$ beam of $20 \mathrm{keV}$ X-rays. Only the edges of the tube $\left(4 \mathrm{~cm}\right.$ on each side) were shielded. Two gas mixtures $\left(50 \% \mathrm{Xe}+30 \% \mathrm{CF}_{4}+20 \% \mathrm{CO}_{2}\right.$ and $\left.65 \% \mathrm{Xe}+25 \% \mathrm{CF}_{4}+10 \% \mathrm{CO}_{2}\right)$ were used. After a certain period of irradiation (from a few minutes up to several hours), the $\mathrm{X}$-ray tube was switched off and the straw tube was irradiated by a collimated beam of ${ }^{55} \mathrm{Fe} X$-rays in the middle of the straw. The pulse height distribution from this ${ }^{55} \mathrm{Fe}$ source was measured before and after the X-ray irradiation and was usually found to be lower after X-ray irradiation In addition the shape of the measured pulse height was asymmetrically broadened towards lower amplitudes. It was found that this effect depends on the gas flow rate, the diameter of the anode wire, the $\mathrm{X}$-ray dose rate and the time after irradiation. Stabilisation sets in after about 2 hours of irradiation and nothing changes for a long time at least up to accumulated doses of $5 \mathrm{C} / \mathrm{cm}$ [13]. Quantitatively these ageing effect are evaluated as a relative decrease of the average amplitude of the pulse height. Fig.21 shows the magnitude of this ageing effect for a gas flow rate of $0.05 \mathrm{~cm}^{3} / \mathrm{min}$ after a period of stabilisation for different dose rates (measured as the values of the electric current in the straw per unit length). One can see that for 
a low dose rate $(0.012 \mu \mathrm{A} / \mathrm{cm})$ no significant ageing effect has been observed. At a dose rate of $2.0 \mu \mathrm{A} / \mathrm{cm}$ the pulse height deterioration is about $10 \%$. This effect very strongly depends on the gas flow rate as shown in Fig. 22. All measurements were done with a $50 \mu \mathrm{m}$ diameter anode. For an anode diameter of $20 \mu \mathrm{m}$ this effect becomes larger by a factor of 2. This effect is transient: after the $\mathrm{X}$-ray tube is switched off the pulse height distribution for ${ }^{55} \mathrm{Fe}$ returns steadily to its initial position and shape. The restoration of the average amplitude as a function of time (typical curve) is shown in Fig. 23 for an anode diameter of $50 \mu \mathrm{m}$ and a gas flow rate of $0.04 \mathrm{~cm}^{3} / \mathrm{min}$ ).

For operation at LHC, the gas flow rate will be about $0.05 \mathrm{~cm}^{3} / \mathrm{min}$. through each straw. The maximum expected current per unit length of straw is about 0.1 $\mu \mathrm{A} / \mathrm{cm}$. One can conclude therefore from Fig. 21 that the transient ageing effect is not more than $2 \%$ for the worst LHC conditions.

Recently new tests were carried out in collaboration with RD10 at CERN and one more effect was found [14]. The gas composition of the mixture used was observed to be somehow modified in the avalanche plasma of the irradiated region in the straw, presumably producing some neutral but electronegative radicals. Many products from $\mathrm{CF}_{4}$ dissociation were observed, using the RD10 mass spectrometer.

From these results we conclude that a more detailed study is needed to evaluate the possible consequences of this $\mathrm{CF}_{4}$ dissociation on the design of the straw gas purification and circulation system, and hence on the long term stability of straw operation at LHC.

\subsection{Space charge effects and straw performance at high fluxes of ionizing particles}

Due to the long drift time of positive ions in the straw tubes, some space charge is accumulated in the gas volume. In the worst case (first straw layers in one of the versions of the barrel TRT for LHC), the intensity of charged particles per unit length is $13 \mathrm{MHz} / 40 \mathrm{~cm}=3.3 \cdot 10^{5}$ particles per $\mathrm{cm}$ per second. The ion space charge arising from such fluxes can change the electric field inside the straw. Dedicated measurements were performed to check the influence of this space charge on the gas gain and the drift time accuracy. The experimental set-up was the same as for the straw drift time accuracy tests (Fig. 24). Two straw tube arrays were placed one behind another in a beam of $2 \mathrm{GeV}$ pions with a width of $15 \mathrm{~mm}$. The straws were irradiated by an ${ }^{55} \mathrm{Fe}$ source $(5.9 \mathrm{keV})$ up to intensities of $2.5 \cdot 10^{5}$ photons per $\mathrm{cm}$ per second, over a length of $22 \mathrm{~mm}$, which covered the beam particle spread across the straws. The total deposited charge is equivalent to a minimum ionizing particle intensity of $7.5 \cdot 10^{5}$ particles per $\mathrm{cm}$ per second (assuming that the average energy deposition of charged particles in the straws is $\sim 2 \mathrm{keV})$.

The time difference between signals from two consecutive straws was measured 
and used to extract the individual straw drift time measurement accuracy $(\sim 150 \mu \mathrm{m})$. Fig. 25 shows the evolution of this accuracy and of the straw signal amplitude as a function of the intensity of straw irradiation. No deterioration of these fundamental straw properties was observed up to intensities of $6 \cdot 10^{5}$ particles per $\mathrm{cm}$ per second.

\subsection{Ion tail measurements in the straw tubes}

One of the most serious problems for the design of the front-end electronics of straw tubes operating at high counting rate is the cancellation of the long ion tails which contribute to the signal. Possible overlapping of ion tails from successive hits in the same straw may lead to a continuous but fluctuating current through the straw. This in turn may result in base-line shifts in the electronic circuits and a resulting effective spread of discriminator thresholds. The inherent fluctuations may spoil the position accuracy of the straws, as obtained from drift-time measurements, but also give rise to fake hits and loss of efficiency. This means that as precise as possible a cancellation of these ion tails has to be built into the front-end electronics especially for DC-coupled systems.

For this reason, very accurate measurements of the straw signal shape were performed over the full duration of the signal.

For cylindrical proportional chambers the signal current is usually expressed as $[15]$ :

$$
I(t)=\frac{I_{0}}{1+t / t_{0}},
$$

with

$$
t_{0}=\frac{a^{2} \ln (b / a)}{2 \mu_{p} V},
$$

where $\mu_{p}=0.6 \mathrm{~cm}^{2} \mathrm{~s}^{-1} \mathrm{~V}^{-1}$ is the Xenon ion mobility. One then obtains $t_{0}=11.4 \mathrm{~ns}$, but this simple evaluation doesn't take into account all physical processes which occur near the anode wire.

Detailed measurements of the current and charge in the Kapton straws were performed for the reference gas mixture $\left(70 \% \mathrm{Xe}+20 \% \mathrm{CF}_{4}+10 \% \mathrm{CO}_{2}\right)$ by irradiating the straw with an ${ }^{55} \mathrm{Fe}$ source. The current amplifier used had a rise-time of $3.5 \mathrm{~ns}$ and did not display any drop in response to a rectangular input pulse for at least $300 \mathrm{~ns}$. The charge-sensitive preamplifier had a rise-time of $20 \mathrm{~ns}$ and a feedback time constant of $18 \mathrm{~ms}$. To minimize any influence from additional circuits on the signal shape, the anode wire was directly connected to these amplifiers. The high voltage was applied to the straw cathode, and the HV power supply was disconnected at the exact time of the measurements, to minimize the impact of any external noise. The measurements were carried out with a $350 \mathrm{MHz}$ digital 
scope. Typical photographs of the observed current and charge pulses are shown in Figs. 26 and 27 respectively. Figure 27 demonstrates that the total charge is collected over $60 \mu \mathrm{s}$. For comparison a photograph of the current pulse in a $80 \% \mathrm{Ar}+20 \% \mathrm{CH}_{4}$ mixture is shown in Fig. 26 (bottom).

One can note the large difference in the current pulse shapes between the Xe and Ar mixtures. In the Xe mixture the electron component of the signal is quite apparent, whereas only the ion current can be distinguished in the Ar mixture. The total collection time in the Xe mixture is $60 \mu \mathrm{s}$ ( $28 \mu \mathrm{s}$ for the Ar mixture). The contribution of the electron current to the total collected charge in the Xe mixture was found to be $3.5 \%$. Total collected charge is $1017 \mathrm{fC}$. for the gas gain $2.5 \cdot 10^{4}$. The data obtained using the current amplifier are shown in Fig. 28 as $1 / \mathrm{I}(\mathrm{t})$, the inverse of the current, versus the time $t$ for Xe and Ar mixtures. This Figure shows that a change of behavior in terms of charge collection happens at times around 120 to $140 \mathrm{~ns}$ for $\mathrm{Xe}$ and $40 \mathrm{~ns}$ for Ar mixtures. The data obtained using the charge preamplifier are shown in Fig. 29 again for Xe and Ar mixtures. An additional change of behavior is observed at a time around $350 \mathrm{~ns}$ for Xe mixtures. The time constants which could be extracted from the data for current and charge using relation (7) are $t_{01}=55 \mathrm{~ns}$ for a time interval less than $120 \mathrm{~ns}$ and $t_{03}=9.5 \mathrm{~ns}$ for a time interval more than 350 ns.

For investigations of ion tail cancellation problems, it is very useful to obtain an analytical expression for the ion current in the straws. The following fit to the experimental points, for a $70 \% \mathrm{Xe}+20 \% \mathrm{CF}_{4}+10 \% \mathrm{CO}_{2}$ mixture and for a $50 \mu \mathrm{m}$ anode wire, can be used ( $\mathrm{I}$ in $\mu \mathrm{A}$ and $\mathrm{t}$ in $\mathrm{ns}$ ):

$$
\begin{gathered}
I(t)=I_{e}+I_{\text {ion }}, \\
I_{\text {ion }}=3.35 e^{-t / 59.7}+0.83 e^{-t / 368}-0.41(t / 29.1)^{2} e^{-t / 29.1}+0.34(t / 29.1)^{3} e^{-t / 29.1}
\end{gathered}
$$

for $\mathrm{t} \leq 500 \mathrm{~ns}$ and

$$
I_{i o n}(t)=\frac{11.48}{1+t / 9.5}
$$

for $500 \mathrm{~ns} \leq \mathrm{t} \leq 60 \mu \mathrm{s}$. This fit very good describes the experimental data, even in the 100-400 ns region. The experimental data and the results from this fit are shown in Fig. 29 (resp. 30) for the charge (resp. current) measurements.

\subsection{Straw tube performance at high counting rate}

To evaluate how to solve the problems which may arise in DC-coupled front-end electronics for straw operation at high counting rate, dedicated MC simulations have been performed. Different pole/zero networks have been optimised through 
simulation in terms of base-line shifts and fluctuations as a function of counting rate. As a result, several discrete front-end electronics prototypes based on discrete elements have been built and operated in a high rate environment. Detailed results of these studies and those to be performed in the near future with integrated electronics will be reported in a future publication. In this section we briefly summarise the main results obtained so far.

With real electronics it is clearly impossible to completely eliminate the ion tail over $60 \mu \mathrm{s}$. The first demand which has to be met is that the total output ion charge be equal to 0 . Secondly, over the first $400-500 \mathrm{~ns}$ the ion current after pole/zero cancellation has to be as close as possible to 0 . One of the most practical solutions to meet these requirements is the implementation into a two-stage pole/zero cancellation network of a double-exponential parametrization of the ion current

$$
I_{\text {ion }}(t)=A_{1} e^{-t / \tau_{1}}+A_{2} e^{-t / \tau_{2}},
$$

with the parameters $A_{1}=3.72 \mu \mathrm{A}, A_{2}=0.46 \mu \mathrm{A}, \tau_{1}=96.4 \mathrm{~ns}$ and $\tau_{2}=1432 \mathrm{~ns}$.

A tunable hybrid preamplifier-shaper chip with these constants has been built for a first set of high rate measurements. The shaped output from this circuit was however much wider (60 ns at the $0.2 \mathrm{keV}$ threshold for a $2 \mathrm{keV}$ signal) than that planned for operation at LHC $(30 \mathrm{~ns})$. In the following, we describe the results of measurements on $80 \mathrm{~cm}$ long straws performed at rates of up to $13 \mathrm{MHz}$, corresponding to approximately the highest charged particle rates in straws expected at the LHC design luminosity.

The main parameters of the chip were tuned to obtain a base-line shift close to 0 at the highest rate. The base line fluctuations were then measured to be about $60 \mathrm{eV}$ r.m.s, close to the level of the electronics noise.

Using the simple experimental setup shown in Fig. 31, the straw drift-time measurement accuracy and efficiency were evaluated as a function of counting rate. The short straw shown in Fig. 31 as Straw 1 had its anode connected to the $80 \mathrm{~cm}$ long anode of Straw 2, which was under irradiation. A collimated ${ }^{90} \mathrm{Sr}$-source of $200 \mu \mathrm{m}$ width was used as a beam to measure the drift-time accuracy. Fig. 32 shows the distribution of hit-arrival times for a standard Xe-mixture and a threshold of 0.2 $\mathrm{keV}$. In Fig. 33 the dependence of the drift-time accuracy upon threshold is shown for Ar-isobutane and Xe-mixtures. The large difference $(170 \mu \mathrm{m}$ for Ar and $230 \mu \mathrm{m}$ for Xe) observed in the drift-time accuracy is explained by the large contribution of multiple scattering of the soft electrons from the source in the Xe-gas which leads to a broadening of the beam. Fig. 34 shows the distribution of hit-arrival times at a $13 \mathrm{MHz}$ counting rate: out-of-time hits appear clearly in the tails of the distribution.

Figs. 35 and 36 illustrate the results quantitatively in terms of the measured drift-time accuracy and efficiency as a function of counting rate. Fig. 35 shows that the worsening of the accuracy per straw is moderate even at rates of $13 \mathrm{MHz}$. 
Table 6: Operating properties of the straw tubes

\begin{tabular}{|c|c|}
\hline Gas mixture & $70 \% \mathrm{Xe}+20 \% \mathrm{CF}_{4}+10 \% \mathrm{CO}_{2}$ \\
\hline Gas gain & $2.5 \cdot 10^{4}$ \\
\hline $\begin{array}{c}\text { Nominal high voltage } \\
\text { Total collection time } \\
\text { for electrons at } \mathrm{H}=2 \mathrm{~T}\end{array}$ \\
\hline $\begin{array}{c}\text { Total collection time } \\
\text { for ions }\end{array}$ \\
\hline $\begin{array}{c}\text { Total collected charge for } \\
6 \mathrm{keV} \text { at a gas gain of } 2.5 \cdot 10^{4}\end{array}$ \\
\hline $\begin{array}{c}\text { Maximum current pulse for } \\
6 \mathrm{keV} \text { at a gas gain of } 2.5 \cdot 10^{4}\end{array}$ \\
\hline $\begin{array}{c}\text { Electron contribution } \\
\text { to the total charge }\end{array}$ \\
\hline
\end{tabular}

Fig. 36 shows however that the measured drift time efficiency is about $37 \%$ at a rate of $13 \mathrm{MHz}$ if the efficiency is defined as the fraction of the hits found within $\pm 2.5 \sigma$ of the expected hit position. Part of the observed loss of efficiency will be recovered by the faster electronics which are expected to be used at LHC. In fact the drift-time measurement efficiency has been predicted to increase from $37 \%$ to $60 \%$ at $13 \mathrm{MHz}$ counting rate by MC-simulations of the LHC front-end electronics.

These first high-rate measurements show that DC-coupled electronics may allow reliable straw tube operation at LHC design luminosity, although at the price of reduced efficiency for drift-time measurements.

Finally, tables 6 and 7 summarise the most important operating properties of the straw tubes presented in this paper. 


\section{Table 7: Operating properties of the straw tubes (continued)}

\begin{tabular}{|c|c|}
\hline $\begin{array}{l}\text { Signal amplitude uniformity } \\
\text { along the straw }\end{array}$ & $\begin{array}{l}\text { Better than } 5 \% \text { r.m.s. for } \\
\text { straws of } 1 \mathrm{~m} \text { length }\end{array}$ \\
\hline $\begin{array}{l}\text { Signal uniformity for } \\
\text { different straws }\end{array}$ & $\begin{array}{l}\text { Better than } 10 \% \\
\text { for } 1 \mathrm{~m} \text { length or less }\end{array}$ \\
\hline $\begin{array}{l}\text { Maximum counting rate } \\
\text { per unit length of straw }\end{array}$ & more than $6 \cdot 10^{5}$ particles $/ \mathrm{cm} / \mathrm{s}$ \\
\hline $\begin{array}{l}\text { Maximum counting rate } \\
\text { for drift time measurements }\end{array}$ & more than $13 \mathrm{MHz}$ \\
\hline $\begin{array}{l}\text { Single straw drift time accuracy } \\
\text { at low counting rate }\end{array}$ & $150 \mu \mathrm{m}$ \\
\hline $\begin{array}{l}\text { Maximum continuous ion current } \\
\text { at highest LHC luminosities }\end{array}$ & $\begin{array}{c}5 \mu \mathrm{A}\left(\text { at gas gain } 2.5 \cdot 10^{4}\right) \\
(1 \text { m straw })\end{array}$ \\
\hline $\begin{array}{l}\text { Max. power dissipation in gas } \\
\text { at highest LHC luminosities }\end{array}$ & $\begin{array}{c}\left.9 \mathrm{~mW} \text { (at gas gain } 2.5 \cdot 10^{4}\right) \\
(1 \mathrm{~m} \mathrm{straw})\end{array}$ \\
\hline $\begin{array}{l}\text { Ageing } \\
\text { Transient ageing } \\
\text { Etching }\end{array}$ & $\begin{array}{l}\text { more than } 5 \mathrm{C} / \mathrm{cm}(8 \text { years at LHC) } \\
\text { no problem at maximum charge particle density } \\
\text { at } \mathrm{LHC}(\text { max current of } 0.1 \mu \mathrm{A} / \mathrm{cm}) \\
\text { more than } 2.5 \mathrm{C} / \mathrm{cm} \text { (no traces of etching seen) }\end{array}$ \\
\hline $\begin{array}{l}\text { Straw counting rate from } \\
\text { neutrons at LHC }\end{array}$ & $\begin{array}{l}\leq 5 \mathrm{keV}-2.4 \% \text { of expected pile-up rate } \\
\geq 5 \mathrm{keV}-20 \% \text { of expected pile-up rate }\end{array}$ \\
\hline Straw radiation resistance & $\begin{array}{l}\text { Fast neutrons: up to } 4 \cdot 10^{14} \\
\text { Slow neutrons: up to } 1.7 \cdot 10^{15} \\
\text { Dose from charged particles: } 80 \mathrm{Mrad}\end{array}$ \\
\hline $\begin{array}{l}\text { Minimum gas flow needed } \\
\text { through the straw }\end{array}$ & $0.05 \mathrm{~cm}^{3} / \mathrm{min}$ per straw \\
\hline
\end{tabular}




\section{Monte-Carlo (MC) simulation of the straw re- sponse}

A dedicated simulation program was developed in order to test in as flexible a way as possible the performance of the straws as tracker elements in a magnetic field and at high counting rate. The description of the physical processes occurring in the straws was made as realistic as possible. The straw simulation model includes:

- The straw attenuation length of $\sim 4 \mathrm{~m}$,

- The signal propagation time of $\sim 4 \mathrm{~ns} / \mathrm{m}$,

- The signal reflection from the far end of the straw,

- The signal shaping $A(t)$ (25 ns width at the base), using a real signal shape from an ${ }^{55} \mathrm{Fe}$ source,

- Ionization in the straws, computed as a number of clusters on the particle track. The probability for a given distance $\mathrm{x}$ between collisions in the gas is

$$
W(x)=\exp \left(-x / x_{0}\right),
$$

where $x_{0}=L / N_{c l}$ ( $\mathrm{L}$ is the length of the track in the straw and $N_{c l}$ is the average number of clusters per unit length. The energy of these clusters, $E_{c l}$, is calculated using the approach of [16],

- Gas gain fluctuations are also taken into account

$$
\sigma_{E_{c l}} \sim 0.25 \cdot \sqrt{E_{c l}}
$$

with $E_{c l}$ in $\mathrm{keV}$ (the energy resolution was measured to be $\sim 25 \%$ at FWHM for cluster energies of $6 \mathrm{keV}$ from an ${ }^{55} \mathrm{Fe}$ source),

- Electronics noise, simulated as

$$
E_{n} \sin (2 \pi \omega t+2 \pi P),
$$

where $E_{n}$ is distributed following a Gaussian with $\sigma=70 \mathrm{eV}$ and $\mathrm{P}$ is a random number between 0 and 1 ,

- The dependence of the drift velocity on the electric field, taken from the MAGBOLTZ program (see section 3.1), 
The output amplitude is then defined as:

$$
A_{\text {out }}(t)=\sum_{i} E_{c l}^{i} A\left(t-t_{i}\right)
$$

where $t_{i}$ is the drift time measured for a given cluster. The contribution of diffusion to the drift time accuracy is at most $30 \mu \mathrm{m}$ and has therefore been neglected. The range of $\delta$-electrons was not included in the simulations (a $1 \mathrm{keV} \delta$ electron in $\mathrm{Xe}$ has a range of about $20 \mu \mathrm{m}$ ).

Fig. 37 shows the simulated straw signal shapes from an ${ }^{55} \mathrm{Fe}$ source (a) and $2 \mathrm{GeV}$ pions crossing the straw at radii of 0 and $1 \mathrm{~mm}$. The straw model was compared to the data from the experimental setup described in Section 3.4 (see also Fig. 18). For $2 \mathrm{GeV}$ pions crossing two consecutive straws on a given side of their anode wires, Fig 38 (a)and Fig. 38 (b) show the expected and measured distribution for the difference in signal arrival times between the two straws, for signals exceeding the discriminator threshold of $0.15 \mathrm{keV}$. The fit to this distribution yields an r.m.s. value of $\sim 200 \mu \mathrm{m}$, in good agreement with the measured individual straw drift time accuracy .

Fig. 39 shows in more detail the expected drift time accuracy per straw as a function of the discriminator threshold. Line 1 corresponds to a straw response simulation without the expected gas gain fluctuations and without electronic noise. Line 2 includes the effect of gas gain fluctuations. Finally line 3 also includes the contribution from electronic noise, and is found to be in excellent agreement with the experimental data. Fig. 40 shows that the straw model also accurately reproduces the measured time-distance relationship for a discriminator threshold of $0.25 \mathrm{keV}$, for tracks crossing the straw on both sides of the anode wire $(+R,-R)$.

\section{Conclusions}

After several years of intensive research and development efforts, the following conclusions have been reached concerning straw tube operation at LHC:

1) Kapton straw tubes of $4 \mathrm{~mm}$ diameter, reinforced with $\mathrm{C}$-fibres, will operate reliably even at the highest LHC luminosities over a period of more than 10 years. The mechanical and electrical properties of these straws are now well understood and the specifications for the operation of a large straw tube system such as that proposed for ATLAS are now close to complete.

2) The straw tubes will operate reliably in the magnetic field of $2 \mathrm{~T}$, and their drift time accuracy has been measured in test beam to be $\sim 150 \mu \mathrm{m}$ to $200 \mu \mathrm{m}$, depending on the exact operating point and on the choice of front-end electronics. 
This performance has been shown to remain practically unaffected by the high local particle fluxes and high total counting rate expected at $\mathrm{LHC}$, except for the drift time measurement efficiency which is expected to drop to $60 \%$ in the worst case (at $13 \mathrm{MHz}$ counting rate).

3) Fully assembled straw tubes have been thoroughly tested for resistance to radiation, both from ionizing particles and neutrons, and also for possible loss of performance due to etching or ageing. With the chosen gas mixture and gas gain, no problem is expected for more than 10 years of operation at LHC design luminosity. The occupancy induced by the high neutron fluence expected in the central cavity has been measured and is expected to increase only by $5 \%$ or less the straw occupancy from ionizing particles.

\section{Acknowledgements}

We thank K. Bussmann, G. Di Tore and A. Konstantinov for their valuable contributions to the preparation of mechanics and electronics for the tests. The research described in this publication was partly made possible thanks to the following funding agencies: The European Union (DGXII), The International Science Foundation (grant NM5J000), The Swedish Natural Science Research Council, The Swedish Council for Planning and Coordination of Research, The UK Particle Physics and Astronomy Research Council. 


\section{References}

[1] J. T. Shank et al., Nucl.Instr. and Meth., A309 (1991) 337.

[2] V. Commishau et al., CERN/DRDC/93-46, RD6/Status Report (1993).

[3] B. Dolgoshein et al., Nucl. Instr. and Meth., A294 (1990) 473.

[4] V. Bondarenko et al., Nucl. Instr. and Meth., A327 (1993) 386.

[5] ATLAS, Letter of Intent, CERN/LHCC/92-4/LHCC/I2 (1992).

[6] S. H. Oh, W. J. Robertson, Nucl. Instr. and Meth., A309 (1991) 368.

[7] S. Majewski et al., Nucl. Instr. and Meth. A348 (1994) 307.

[8] V. Bychkov et al ., Nucl. Instr. and Meth., A325 (1989) 158.

[9] J. Giddings, Ph. D. Thesis, UCL, 1992.

[10] S. F. Biagi, Nucl. Instr. and Meth., A283 (1989) 716.

[11] U. J. Becker, J. P. Rodin and B. R. Smith, Nucl. Instr. and Meth.,A335(1993)439.

[12] S. Boyrinov et al., GEM TN-93-345, (1993).

[13] V. G. Bondarenko et al., CERN-PPE/91-191, (1991).

[14] M. Carpeans et al., CERN-PPE/93-136 (1993).

[15] V. Radeka, Ann. Rev. Nucl. Part. Sci., 38 (1988) 217.

[16] W. W. M. Allison and J. H. Cobb, Ann. Rev. Nucl. Part. Sci., 30 (1980) 253. 
Figure captions

Fig. 1 The straw manufacturing procedure.

Fig. 2 Cut through the straw wall.

Fig. 3 Elongation versus time of a $50 \mathrm{~cm}$ long straw under a load of $200 \mathrm{~g}$.

Fig. 4 Humidity versus time during measurements of fig. 3 .

Fig. 5 Gas gain uniformity along three straws as a function of humidity. Straws 1 and 2 without carbon fibre reinforcement, straw 3 with carbon fibre reinforcenment.

Fig. 6 Gas gain uniformity along three straws as a function of temperature.

Fig. 7 Dependence of straw gas gain on wire eccentricity.

Fig. 8 Electrical connection of straw to HV supply and preamplifier.

Fig. 9 Time needed to disconnect HV fuse versus current through the fuse.

Fig. 10 Electronics connection for the cathode read-out. In the case of an outer layer with low resistance it is divided into rings of $15 \mathrm{~mm}$ length.

Fig. 11 Signal shapes from anode and cathode for a source position at the middle of a ring.

Fig. 12 Amplitude distributions over the cathode channels for different positions of the collimated source and for a cathode subdivided into roings.

Fig. 13 Amplitude distributions over the cathode channels for different positions of the collimated source and for a single cathode with a resistance of $1500 \Omega / \mathrm{cm}$.

Fig. 14 Module of electron drift velocity in a magnetic field $\mathrm{H}=20 \mathrm{kG}$ as a function of electric field (experimental data and MAGBOLTZ calculations).

Fig. 15 Lorentz angle as a function of electric field for $\mathrm{H}=20 \mathrm{kG}$ and the reference gas mixture of $70 \% \mathrm{Xe}+20 \% \mathrm{CF}_{4}+10 \% \mathrm{CO}_{2}$ (experimental data and MAGBOLTZ calculations).

Fig. 16 Module of electron drift velocity for $\mathrm{H}=0$ as a function of electric field (experimental data and MAGBOLTZ calculations). 
Fig. 17 MAGBOLTZ calculation of drift velocity component parallel to electric field as a function of electric field for $\mathrm{H}=0$ and $20 \mathrm{kG}$.

Fig. 18 Experimental set-up for the measurement of straw sensitivity to neutrons.

Fig. 19 Straw spectra for different combinations of absorbers in the set-up of fig. 18 ; 1 - without shield and moderator , 2 - lead shield of $100 \mathrm{~mm}, 3$ - lead shield of $150 \mathrm{~mm}, 4$ - lead shield of $200 \mathrm{~mm}, 5$ - lead shield of $200 \mathrm{~mm}$ and polystyrene moderator of $70 \mathrm{~mm}$.

Fig. 20 Predicted counting rates and occupancies induced by charged particles and neutrons at $\mathrm{L}=10^{34} \mathrm{~cm}^{-2} \mathrm{~s}^{-1}$, for a $50 \mathrm{~cm}$ long radial straw

Fig. 21 Dependence of the transient ageing effect on the X-ray dose rate density for a gas flow rate of $0.05 \mathrm{~cm}^{3} / \mathrm{min}$

Fig. 22 The dependence of the transient radiation ageing effect on the gas flow rate for a $2.0 \mu \mathrm{A} / \mathrm{cm}$ straw current density

Fig. 23 Example of recovery as a function of time from the transient ageing effect using th pulse height measurement from a ${ }^{55} \mathrm{Fe}$ source

Fig. 24 Experimental setup for measurements of the straw drift time accuracy.

Fig. 25 Amplitude of signal from an ${ }^{55}$ Fe source (a) and drift time accuracy (b) as a function of charged particle rate per unit straw length.

Fig. 26 Photographs of current seen in a straw for a $70 \% \mathrm{Xe}+20 \% \mathrm{CF}_{4}+10 \% \mathrm{CO}_{2}$ mixture (a) and for a $80 \% \mathrm{Ar}+20 \% \mathrm{CH}_{4}$ mixture (b).

Fig. 27 Photographs of charge collected from a straw using a charge sensitive preamplifier. Top $-0.5 \mu \mathrm{s} /$ div, bottom - $10 \mu \mathrm{s} / \mathrm{div}$

Fig. 28 Inverse value of current measured as a function of time for a $70 \% \mathrm{Xe}+20 \% \mathrm{CF}_{4}+10 \% \mathrm{CO}_{2}$ mixture (1) and for a $80 \% \mathrm{Ar}+20 \% \mathrm{CH}_{4}$ mixture (2)

Fig. 29 Charge collected in straw as a function of time for a $70 \% \mathrm{Xe}+20 \% \mathrm{CF}_{4}+10 \% \mathrm{CO}_{2}$ mixture (1) and for a $80 \% \mathrm{Ar}+20 \% \mathrm{CH}_{4} \mathrm{mix}-$ ture (2) (dashed line is an ad hoc fit) 
Fig. 30 Ion current measured as a function of time (line is an ad hoc fit).

Fig. 31 Experimental set-up for the straw drift time accuracy measurements at high counting rates.

Fig. 32 Hit arrival time distribution for a low counting rate

Fig. 33 Measured drift-time accuracy for Ar and Xe mixtures and for a low counting rate

Fig. 34 Hit arrival time distribution for a counting rate of $13 \mathrm{MHz}$

Fig. 35 Measured dtift-time accuracy as a function of counting rate, compared to $\mathrm{MC}$ predictions.

Fig. 36 Measured efficiency for the drift-time hits as a function of counting rate, compared to MC predictions.

Fig. 37 Predicted straw signal shapes after preamplifier-shaper for an ${ }^{55} \mathrm{Fe}$ source and for $2 \mathrm{GeV}$ pions crossing the straw at radii of 0 and $1 \mathrm{~mm}$

Fig. 38 Predicted (a) and measured (b) track position difference between two adjacent and parallel straws in test beam.

Fig. 39 Comparison, as a function of threshold, of drift-time measurements accuracy for data and Monte-Carlo :

1 - without noise nor gas gain fluctuations, 2 - without noise, 3 - with both noise and gas gain fluctuations.

Fig. 40 Measured and predicted ( $\mathrm{r}-\mathrm{t}$ ) dependence in a straw. 